\title{
Antioxidant Activity and Immunomodulatory of Extracts From Roots of Actinidia kolomikta
}

\author{
Hongyi Sun ${ }^{1}$, Shaofei Wang ${ }^{1}$, Shuhong $\mathrm{Li}^{1}$, Xi Yuan ${ }^{1}, \mathrm{Jian} \mathrm{Ma}^{1}$ \& Zhenya Zhang ${ }^{1}$ \\ ${ }^{1}$ Graduate School of Life and Environmental Sciences, University of Tsukuba, Ibaraki, Japan \\ Correspondence: Zhenya Zhang, Graduate School of Life and Environmental Sciences, University of Tsukuba, \\ Ibaraki 305-8577, Japan. Tel: 81-29-853-4712. E-mail: zhang.zhenya.fu@u.tsukuba.ac.jp
}

Received: January 30, 2013 Accepted: April 4, 2013 Online Published: April 23, 2013

doi:10.5539/ijb.v5n3p1 URL: http://dx.doi.org/10.5539/ijb.v5n3p1

\begin{abstract}
Four extracts (AEA, AEB, AEC and AED), whose yields were 2.05\%, 6.35\%, 1.38\% and 3.55\%, respectively, were isolated and purified from the roots of Actinidia kolomikta in order to detect their antioxidant and immunomodulatory characteristics. In this study, AEC possessed the highest SOD-like activity $(840.2 \mathrm{U} / \mathrm{mg})$ and also showed stronger radical-scavenging activity (EC50, $152.2 \mu \mathrm{g} / \mathrm{ml})$. In addition, for anti-proliferation, DLD-1 cells survival decreased to $30.8 \%$ at $50 \mu \mathrm{g} / \mathrm{ml}$ for $48 \mathrm{~h}$ by AEC. In this condition, the percentages of apoptosis cells were significantly increased from $0.85 \%$ to $17.30 \%$. Moreover, AEB improved nitric oxide production and was shown to be more effective for immunomodulatory activity on macrophage survivals. The results indicate that all extracts from the roots of A. kolomikta exhibited strong antioxidant and immunomodulatory activities. These could provide a theoretical basis for $A$. kolomikta to be considered a nutritious functional material.
\end{abstract}

Keywords: Actinidia kolomikta roots, antioxidant activities, DLD-1 cells, macrophages, immunomodulatory activities

\section{Introduction}

Cancer, in today's world is to the human life threat bigger diseases, medical science is also one of the important research subjects. Since the anti-cancer ingredients vinblastine from Vinca was found, the international scientific community has paid a great attention to the study of plant medicine. Many countries, scientists began to use various methods of screening anticancer active ingredient from a large number of plants, and have made many achievements. Among these, the genus Actinidia (Actinidiaceae) consists of over 58 species, which are widely distributed in the Asian continent (Xu et al., 2009).

Actinidia kolomikta (Japanese: Miyamamatatabi) is native to temperatemixed forests of the Russian Far East, Korea, Japan and China (Eastern Asiatic Region) (Flora of China Vol. 12 Page 335, 338), is a species of deciduousdioeciouswoodyvine in the genus Actinidia. Actinidia kolomikta is a very long-lived woody scrambling vine and creeper, which ultimately grows to $8-10 \mathrm{~m}$ (about 26 to 33 feet) and also have strong cold resistance, and can even survive at about $-40^{\circ} \mathrm{C}$ in winter. A. kolomiktacan effectively block the formation of carcinogenic nitrosamines in the human body. Compared with blocking rate of Vitamin $\mathrm{C}$ and lemon juice which is only $5 \%$, its blocking rate can amount to $98 \%$. Even if the vitamin C in the A. kolomikta is broken, its nitrosamine synthesis blocking rate is still up to $79 \%$. This confirms that abundant vitamin $\mathrm{C}$ is in the fruit inside. Besides, at least another two kinds of active substances can block the synthesis of carcinogenic nitrosamines. Therefore, for vulnerable to the carcinogenic nitrosamines infiltration of chronic atrophic gastritis, gastric ulcer, gastric polyps, chronic hepatitis $\mathrm{B}$, cirrhosis and other patients, A. kolomikta shows ideal anti-cancer effect. The roots of $A$. kolomikta are used as traditional medicines for the treatment of diabetes, inflammation and cancer in Laos. Up to now there has been no systemic research on its chemical constituents and bioactivities; particularly no work has been reported in the literature in which the antioxidant and anti-proliferative properties of $A$. kolomikta have been studied in vitro or in vivo. For the above reasons, the immunomodulatory activity of extractions from the $A$. kolomikta can be of great value for the medicinal and food industries.

Cancer is one of the leading causes of death in the world. The characteristic of cancer cells is unlimited, endless proliferation, so that make the patient's body nutrients mass consumed. Cancer cells release a variety of toxins producing a range of symptoms. Cancer cells can also be transferred throughout the body lead to the growth and reproduction, body weight loss, weakness, anemia, loss of appetite, fever and severe organ dysfunction. Cancer 
can be prevented through the following aspects: Blocking the carcinogenic activity of carcinogenic agents, inhibition of DNA adduct formation, improving the level of DNA repair and antioxidant activity, inhibition of cell proliferation, inhibition of proto-oncogene activation and tumor suppressor gene inactivation, and modulation of immune correct methyl balance anti-tumor invasion and metastasis. Anti-cancer drugs are known to cause severe adverse effects such as immune system damage, which constrains their use in tumor treatment. Therefore, it is very important to investigate novel anti-tumor drugs with improved immunity potential without harming the host (Yang, Guo, Zhang, \& Wu, 2007).

Polysaccharides are a kind of molecular mechanism complex and huge carbohydrate substances, which through the reactions of condensation and dehydration of multiple monosaccharide molecular. Many polysaccharides and polysaccharide-protein complexes, isolated from mushrooms, fungi, yeasts, algae, lichens and plants, have attracted more attention recently in biochemical and medical areas due to their immunomodulatory and anti-cancer effects (Liu, Ooi, Liu, \& Chang, 2000; Wasser, 2002; Leung, Liu, Koon, \& Fung, 2006). Flavonoids in the human body cannot be directly synthesized, only be obtained from food products, while the compounds of the flavonoid is widely present in the plant body, so recently, scientists are actively concerned extracting from the plant body of high purity and strong activity of natural flavonoids ingredients, and further processed to have anti-cancer, anti-aging, regulating endocrine-specific features such as health food. The immunological research shows that the Japanese prostate cancer mortality rate is low because of regular consumption of soy products containing flavonoids. Although the substance of flavonoids is not the composition of the human body, that has the effect of preventing cancer. Due to the human body absorb heterocyclic amine material available in the human body in the liver enzyme activation P450, which make mutate so as to cause cancer. And polyphenol and flavonoids can significantly inhibit the activity of this enzyme. When cultured cancer, if added flavonoids, that can effectively inhibit the proliferation of cancer cells. Its mechanism is by regulating the cell cycle, the cells from the $\mathrm{C} 1$ state transition into the normal state, thereby inhibiting its growth.

The objective of this study is to investigate antioxidant activity, anti-proliferative activity and immunological activity of the extractions of $A$. kolomikta with ethanol-hot water combination extraction on human colon cancer DLD-1 cells and proliferation of macrophage RAW 264.7 cells for the valuation of its potential as a natural immunomodulator source for medicinal and food industry.

\section{Materials and Methods}

\subsection{Materials and Reagents}

2,2-Diphenyl-1-picryl-hydrazyl (DPPH), Minimum Essential Medium Eagle (MEM) medium, Folin-Ciocalteureagent, 6-Hydroxy-2,5,7,8-tetramethlchroman-2-carboxylic acid (Trolox), Propidium iodide (PI), RPMI-1640 Medium, fetal bovine serum (FBS) and penicillin-streptomycin solution were purchased from Sigma Aldrich, Inc. (Saint Louis, MO, USA). SOD Assay Kit-WST, Cell Counting Kit-8 and Hoechst 33258 solutions were purchased from Dojindo Molecular Technologies, Inc. (Kumamoto, Japan). Gallic acid was purchased from Nacalai Tesque, Inc. (Kyoto, Japan).Lip polysaccharide (LPS) from E, coli 055 was purchased from Wako Pure Chemical Industries, Ltd. (Osaka, Japan). Doxorubicin (DOX) was purchased from TopoGEN, Inc. (Florida, USA).

\subsection{Cell Line}

A DLD-1 human colon cancer cell line was obtained from the Cell Resource Center for Biomedical Research, Aging and Cancer, Tohoku University (Japan). It was grown in RPMI1640 medium containing 10\% fetal bovine serum (FBS) and $1 \%$ penicillin/streptomycin. Culture was maintained at $37^{\circ} \mathrm{C}$ in a humidified $5 \% \mathrm{CO}_{2}$ atmosphere (ESPEC $\mathrm{CO}_{2}$ Incubator). The cells were cultured for 2-3 days to reach the logarithmic phase and used for experiments. The cells were passaged twice a week. The macrophage cell line, RAW264.7, was bought from Riken Cell Bank (Tsukuba, Japan) and maintained in Minimum Essential Medium Eagle medium (Sigma Chemical Co., Saint Louis, MO) containing 10\% (v/v) fetal bovine serum and antibiotics (consisting of 100 units $/ \mathrm{ml}$ penicillin and $100 \mu \mathrm{g} / \mathrm{ml}$ streptomycin) at $37^{\circ} \mathrm{C}$ in $5 \%(\mathrm{v} / \mathrm{v}) \mathrm{CO}_{2}$.

\subsection{Extraction, Isolation and Purification of Polysaccharides}

The roots of $A$. kolomikta, used as substrate, were purchased from Indochina. Before the experiments and after drying, all the roots were milled for 10 min using a micromill (1029-B type, Yoshida Seisakusho Co., Ltd., Japan) and powder with particle diameter smaller than $0.2 \mathrm{~mm}(80$-mesh) was used in the following extraction preparation.

For the first sample, AEA, the residue was removed by ethanol-hot water combination extraction. The roots (20 g) were extracted with $80 \%$ ethanol $(200 \mathrm{ml})$ at $24^{\circ} \mathrm{C}$ for $24 \mathrm{~h}$ to remove free sugars and the pigments (Zhao et 
al., 2005), and the supernatant was concentrated by rotary evaporator and dried by freeze dryer to get the $80 \%$ ETOH-hot water extract fraction A of A. kolomikta (AEA).

For the second sample, AEB, the residue was extracted by boiling water $(200 \mathrm{ml})$ for $2 \mathrm{hrs}$, after that the aqueous extract was centrifuged at $6000 \mathrm{rpm}, 4^{\circ} \mathrm{C}$ for $10 \mathrm{~min}$ and then filtered. Lastly, the filtrate was concentrated and lyophilized to obtain water extraction fraction $\mathrm{B}$ of $A$. kolomikta.

For the third sample, AEC, the residue was removed by centrifugation $\left(3500 \mathrm{rpm}, 4^{\circ} \mathrm{C}\right.$ for $\left.10 \mathrm{~min}\right)$, then extracted with $80 \%$ ethanol $(200 \mathrm{ml})$ at $24^{\circ} \mathrm{C}$ for $24 \mathrm{~h}$, the supernatant was concentrated by rotary evaporator and dried by freeze dryer to get the $80 \%$ ETOH-hot water extract fraction C of $A$. kolomikta.

For the last sample, AED, the residue was centrifuged at $3500 \mathrm{rpm}, 4^{\circ} \mathrm{C}$ for $10 \mathrm{~min}$, then washed with distilled water $(200 \mathrm{ml})$, concentrated by rotary evaporator and dried by freeze dryer to obtain the $80 \%$ ETOH-hot water extract fraction D of A. kolomikta.

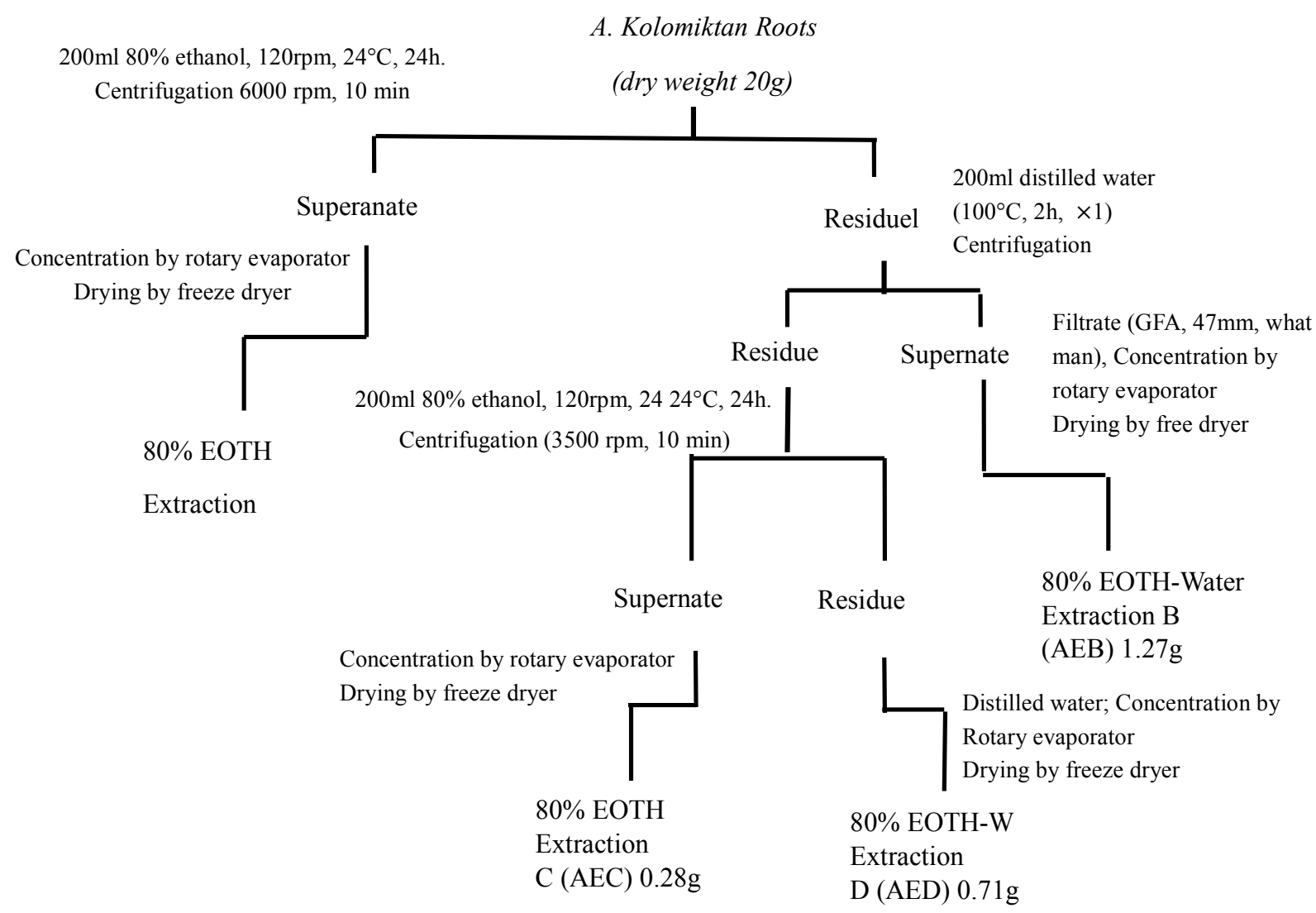

Figure 2-1 Summarized extraction procedure of AEA, AEB, AEC and AED from the root of $A$. kolomikta

\subsection{The Determination of the Main Antioxidant Activity Components}

\subsubsection{Determination of the Crude Polysaccharide Contents}

The polysaccharide content was quantified with a modified phenol-sulfuric acid method according to the literature (Dubois et al., 1956). The extract was treated with $87.5 \%$ ethanol and stored overnight at $4{ }^{\circ} \mathrm{C}$, and then centrifuged at $7000 \mathrm{rpm}$ for $30 \mathrm{~min}$. The precipitate was washed twice with absolute ethanol, and then evaporated in vacuum to remove the residual ethanol. The obtained precipitate polysaccharide was dissolved in distilled water, and added to $1 \mathrm{ml}$ of polysaccharide solution contained $0.5 \mathrm{ml}$ of a $5 \%$ phenol solution and $2.5 \mathrm{ml}$ of $98 \%$ concentrated sulfuric acid, after mixing, incubated at $100^{\circ} \mathrm{C}$ in water bath for $15 \mathrm{~min}$. After cooling to room temperature, the optical density (O.D.) of the mixture was determined at $490 \mathrm{~nm}$ with a spectrophotometer and the total polysaccharide content was calculated with D-glucose as the standard. 


\subsubsection{Determination of the Total Polyphenols Contents}

Total polyphenols content was determined using the Folin-Ciocalteu method (Mau, Lin, \& Song, 2002). $0.1 \mathrm{ml}$ extract fraction with $7.9 \mathrm{ml}$ distilled water and $0.5 \mathrm{ml}$ Folin-Cilcalteu reagent (1:1 with distilled water) were added and mixed in a sealed glass tube. $1.5 \mathrm{ml}$ of sodium carbonate $(20 \mathrm{~g} / 100 \mathrm{ml})$ was added $1 \mathrm{~min}$ later and then mixed, allowed to incubate for $2 \mathrm{hrs}$ at room temperature in dark. The absorbance was measured at $765 \mathrm{~nm}$ and using gallic acid as standard.

\subsubsection{Determination of the Total Flavonoids Contents}

A modified method (Zhang \& Li, 2007) was used for assay. $1 \mathrm{ml}$ flavonoids diluted solution containing, $10 \mathrm{ml}$ of $30 \%(\mathrm{v} / \mathrm{v})$ ethanol and $0.7 \mathrm{ml}$ of $5 \%(\mathrm{w} / \mathrm{w}) \mathrm{NaNO}_{2}$ were mixed for 5 min, after that $0.7 \mathrm{ml}$ of $10 \% \mathrm{AlCl}_{3}(\mathrm{w} / \mathrm{w})$ was added. Then $5 \mathrm{ml}$ of $1 \mathrm{~mol} / 1 \mathrm{NaOH}$ was mixed 6 min later. Ultimately, the solution was diluted to $25 \mathrm{ml}$ with $30 \%(\mathrm{v} / \mathrm{v})$ ethanol before measurement. After $10 \mathrm{~min}$ standing, the absorbance of the solution was determined at $500 \mathrm{~nm}$ with a spectrophotometer. The results were expressed as $\mathrm{mg}$ rutin equivalent (mg rutin /g extract) dry weight by comparison with rutin standard curve.

\subsection{The Determinations of the Antioxidant Properties}

\subsubsection{Assays of SOD-Like Activity}

SOD-like activity of the extracts was measured by the SOD Assay Kit-WST according to the technical manual provided by Dojindo Molecular Technologies, Inc. Firstly, $20 \mu 1$ of sample solution was added to blank 2 well and each sample, meanwhile $20 \mu \mathrm{l}$ of double distilled water was added to each blank 1 and blank 3 well in a 96-well plate. After that, $200 \mu \mathrm{l}$ of WST working solution was added to each well, mixed waiting for further processing. Sequently, $20 \mu 1$ of dilution buffer was added to each blank 2 and blank 3 well, and $20 \mu$ of enzyme working solution was added to each sample and blank 1 well. The plate was incubated at $37^{\circ} \mathrm{C}$ for 20 min and the optical density (O.D.) was measured at $450 \mathrm{~nm}$ using a microplate reader (Bio-Rad Model 550, USA). The SOD-like activity was calculated by the following equation:

$$
\text { SOD activity (inhibition rate \%) }=\left\{\left[\left(A_{\text {blank } 1}-A_{\text {blank } 3}\right)-\left(A_{\text {sample }}-A_{\text {blank } 2}\right)\right] /\left(A_{\text {blank } 1}-A_{\text {blank } 3}\right)\right\} \times 100
$$

$\mathrm{A}_{\text {blank } 1}, \mathrm{~A}_{\text {blank2 }}, \mathrm{A}_{\text {blank } 3}$ and $\mathrm{A}_{\text {sample }}$ were the absorbances of blank 1, blank 2, blank 3 and sample wells. 1 Unit of SOD activity was defined as the amount of enzyme having a 50\% inhibitory effect on WST-1.

\subsubsection{Assays of DPPH Radical Scavenging Activity}

DPPH scavenging activity was determined according to (Nakajima et al., 2007; Yang et al., 2006). Briefly, Volumes of $80 \mu \mathrm{l}$ of $0.5 \mathrm{mM}$ DPPH in MeOH solutions and $80 \mu \mathrm{l} 0.1 \mathrm{M}$ MES buffer in $50 \% \mathrm{MeOH}$ (pH 6.0) were added into 96-well plate, an aliquot of sample solution was added to make up to200 $\mu 1$. After 10 min of reaction, the optical density (O.D.) was determined at a wavelength of $570 \mathrm{~nm}$ with a microplate reader. The DPPH radical-scavenging activity was calculated by the following equation:

$$
\text { DPPH-scavenging activity }(\%)=(1-A \text { sample/A control }) \times 100
$$

The scavenging activity of the sample was expressed as a $50 \%$ effective concentration (EC50), which represented the sample concentration $(\mu \mathrm{g} / \mathrm{ml})$ inhibiting $50 \%$ of the DPPH radical activity.

\subsection{Cell Evaluation}

\subsubsection{Assays of WST-8}

The effect of the four extract fractions of A. kolomikta on the anti-proliferation of colon cancer cell line DLD-1was estimated using the Cell Counting Kit-8 (Dojin East, Tokyo).The WST-8 colorimetric assay was performed according to the instructions of the manufacturer. DLD-1 cells were cultured in RPMI-1640 medium in a $5 \% \mathrm{CO}_{2}$ atmosphere at $37^{\circ} \mathrm{C}$ to logarithmic phase. After harvested, an aliquot (100 $\left.\mu \mathrm{l}\right)$ of DLD-1 cells suspension at a density of $5 \times 10^{4} \mathrm{cells} / \mathrm{ml}$ were dispensed into a 96 -well plate and pre-incubated in a $5 \% \mathrm{CO}_{2}$ atmosphere at $37^{\circ} \mathrm{C}$ for $24 \mathrm{hrs}$. Then cells were exposed to various concentrations of extracts $(12.5,25,50 \mu \mathrm{g} / \mathrm{ml})$ at various durations $12 \mathrm{~h}, 24 \mathrm{~h}$, and $48 \mathrm{hrs}$. After incubation, $10 \mu \mathrm{l}$ of Cell Counting reagent solution was added at $37^{\circ} \mathrm{C}$ for $4 \mathrm{~h}$. The cell viability was assessed by the optical density (O.D.) at $450 \mathrm{~nm}$ with a microplate reader (Bio-Rad Model 550). Cell viability was calculated by the following equation:

$$
\text { Cell survival rate }(\%)=\left(A_{\text {sample }}-A_{\text {blankl } 1}\right) /\left(A_{\text {control }}-A_{\text {blank } 2}\right) \times 100
$$

$\mathrm{A}_{\text {sample }}$, optical density value of test samples with cells, $\mathrm{A}_{\text {blank1 } 1}$, optical density value of samples with medium, $\mathrm{A}_{\text {control}}$, optical density value of control with cells, $\mathrm{A}_{\text {blank }} 2$, optical density value of control with medium. Data were expressed as percentages of control. 


\subsubsection{Detection of Apoptosis by Flow Cytometry}

Active components AEA and AEC were investigated in this follow-up study. The flow cytometry assay was determined with some modification according to (Zhang, 2005). Briefly, DLD-1 cells $\left(1 \times 10^{5} \mathrm{cells} / \mathrm{ml}\right)$ were incubated with extracts of 25 and $100 \mu \mathrm{g} / \mathrm{ml}$ for 48 hin 6-well plate. Then washed by cold PBS (-), cells were fixed in $70 \%$ ethanol at $4^{\circ} \mathrm{C}$ for 4 hrs. Harvested cells were incubated with PI solution $(20 \mu \mathrm{g} / \mathrm{ml})$ at $4{ }^{\circ} \mathrm{C}$ for 30 min. The DNA histograms were plotted by flow cytometry (BDOLSR, BD Biosciences). The values of 10,000 cells from each sample were collected and the percentage of apoptotic cells was analyzed using Cell Quest software (Becton Dickinson).

\subsubsection{Macrophage RAW 264.7 Cells Proliferation}

The macrophage RAW 264.7 cells were cultured in 96-well cell plates at a density of $5 \times 10^{4}$ cells $/ \mathrm{ml}$ in a $5 \% \mathrm{CO}_{2}$ atmosphere for $24 \mathrm{~h}$ prior to drug exposure then incubated with variousconcentrations of AEA, AEB, AEC and AED fractions $(1.56,3.12,6.25,12.525$ and $50 \mu \mathrm{g} / \mathrm{ml})$. Controls were treated with distilled water or DMSO, whose final concentration was less than $1 \%(\mathrm{v} / \mathrm{v})$. After indicated concentration and time drug exposure, $10 \mu \mathrm{l}$ of WST-8 reagent was added and incubated for $4 \mathrm{~h}$ at $37^{\circ} \mathrm{C}$. Cell viability was determined by the optical density (O.D.) at $450 \mathrm{~nm}$ with a microplate reader. Data were expressed as percentages of control.

\subsection{Statistical Analysis}

The data were expressed as mean \pm standard deviation (SD) and examined for their statistical significance of difference with ANOVA and a Tukey post-hoc test. P-values of less than 0.05 were considered to be statistically significant.

\section{Results and Discussion}

\subsection{Contents of Antioxidant Components}

Table 1 shows the extraction yields, the polysaccharide contents, the total polyphenols contents and the total flavonoids contents of AEA, AEB, AEC and AED using four different methods of extraction from A. kolomikta with an ethanol-hot water combination. As it shows in Table 1, the yields of AEA, AEB, AEC and AED under ethanol-hot water combination extraction were considerably different by extraction methods and retrieved $2.05 \%$, $6.35 \% 1.38 \%$ and $3.55 \%$, respectively. The yield of AEB was 6.35\%, 4.6 times as high as that AEC which had the least yield. It is easy to demonstrate that the extraction yields of AEB and AED which were obtained from the residues of ethanol precipitation and water extraction were higher than the AEA and AEC fractions which were extracted from the supernates. The order of the four fractions extracted from A. kolomikta was: AEB $>$ AED $>$ AEA $>$ AEC.

The polysaccharide contents of AEA AEB AEC and AED were $161.72 \pm 0.21,234.71 \pm 0.13,181.83 \pm 0.16$ and $234.14 \pm 0.09 \mathrm{mg} / \mathrm{g}$, respectively. The contents of polysaccharide in AEB and AED were similar and higher than that in AEA and AEC. The polysaccharide does not dissolve in $80 \%$ ethanol therefore AEB and AED could be considered crude polysaccharide fractions. The order of four fractions extracted from A. kolomikta was: AEB > AED $>$ AEC $>$ AEA.

It has been confirmed, polyphenol compounds have a variety of physiological functions and medicinal value that can prevent free radical oxidation of human pathology, physiology and radicals closely related. Therefore, polyphenol and flavonoids can effect on the prevention and treatment of diseases, as well as human health positive significance. The total polyphenols contents of AEA, AEB AEC and AED were 114.95 $\pm 0.32,175.7 \pm$ $0.25,236.6 \pm 0.17$ and $164.6 \pm 0.20 \mathrm{mg}$ gallic acid $/ \mathrm{g}$, respectively. The highest total of polyphenols was remarkably found in the AEC fraction and was twice as high as AEA. The order of four fractions extracted from A. kolomikta was: AEC $>$ AEB $>$ AED $>$ AEA.

Flavonoids, also collectively known as vitamin $\mathrm{P}$, are most commonly known for their antioxidant activity in vitro. In recent years, attention of human beings on flavonoids' natural biological activity has increased. It has now been confirmed, Flavonoids have a variety of physiological functions and medicinal value also can prevent free radical oxidation of human pathology, physiology and free radicals. So there is a close relationship between flavonoid compounds for the prevention of disease and the health of the people has a positive significance. The antioxidant abilities of flavonoids in vitro are higher than those in vitamin $\mathrm{C}$ and $\mathrm{E}$. The total flavonoids contents of AEA, AEB AEC and AED were $349.92 \pm 0.42,203.33 \pm 0.06,507.59 \pm 0.11$ and $247.81 \pm 0.14 \mathrm{mg}$ rutin $/ \mathrm{g}$, respectively. The total flavonoids content in AEC were higher than AEA AEB and AED. The order of four fractions extracted from A. kolomikta was: AEC > AEA > AED > AEB.

It was reported that polyphenols are strong radical scavengers and metal chelators in model chemical systems 
(Su et al., 2006). It was also reported that there was a positive, significant linear relationship between total polyphenol and antioxidant activity by comparing characteristics of snake and kiwi fruits (Gorinstein et al., 2009), because the polyphenols were the dominant antioxidant components in medicinal herbs (Cai et al., 2004).

Compared with other methods (Sousa et al., 2008), ethanol-hot water combination extraction at low temperature was a better method to extract polysaccharide, polyphenols and flavonoids that to obtain higher antioxidant content. Compared with the order of the contents of AEA, AEB, AEC and AED, the primary antioxidant components follow no rules to conclusion and therefore cannot indicate which one possesses the highest yield. So multiple reaction characteristics and mechanisms would be involved, no single assay could accurately reflect all antioxidants in a mixed or complex system. Demonstrating the antioxidant activity through cell experiments is the next step.

Table 1. Extraction yields, polysaccharide contents, total polyphenols contents and total flavonoids contents of AEA, AEB, AEC and AED using four different methods of extraction from A. kolomikta

\begin{tabular}{lllll}
\hline Sample & $\begin{array}{l}\text { Extraction } \\
\text { yields }(\%)\end{array}$ & $\begin{array}{l}\text { Polysaccharides } \\
\text { concentration }(\mathrm{mg} / \mathrm{g})\end{array}$ & $\begin{array}{l}\text { Polyphenols content } \\
(\mathrm{mg} \text { gallic acid/g) }\end{array}$ & $\begin{array}{l}\text { Flavonoids content } \\
(\mathrm{mg} \text { rutin/g) }\end{array}$ \\
\hline AEA & 2.05 & $161.72 \pm 0.21$ & $114.95 \pm 0.32$ & $349.92 \pm 0.42$ \\
AEB & 6.35 & $234.71 \pm 0.13$ & $175.74 \pm 0.25$ & $203.33 \pm 0.06$ \\
AEC & 1.38 & $181.83 \pm 0.16$ & $236.67 \pm 0.17$ & $507.59 \pm 0.11$ \\
AED & 3.55 & $234.14 \pm 0.09$ & $164.68 \pm 0.20$ & $247.81 \pm 0.14$ \\
\hline
\end{tabular}

The values are presented as means \pm S.D.

\subsection{Antioxidant Activity of Four Extracts}

\subsubsection{SOD-Like Activity Assays}

SOD is an antioxidant enzyme that catalyzes the dismutation of superoxide anions into $\mathrm{O}_{2}$ and $\mathrm{H}_{2} \mathrm{O}_{2}(\mathrm{Mates} \mathrm{J}$ M, Perez-Gomez C, \& Nunez de Castro I, 1999). It is the primary material which scavenges free radical. SOD-like is a non-enzyme-small molecule super antioxidant that has similar function with SOD, also can promote the synthesis of SOD in the human body. Furthermore, it cannot damage human gastric easily, is conducive to the absorption of the body's normal metabolism. As shown in Figure 1, comparing the four fractions, AEC represented the highest antioxidant activity and the SOD-like activities were $840.2 \mathrm{U} / \mathrm{mg}$. In descending order, AED, AEA and AEB showed lower SOD-like activities, which were $732.6 \mathrm{U} / \mathrm{mg}, 403.8 \mathrm{U} / \mathrm{mg}$ and 368.1 U/mg, respectively. Compared with the results of Table 1, it can be figured out the order of the antioxidant compounds is $\mathrm{AEC}>\mathrm{AED}>\mathrm{AEA}>\mathrm{AEB}$, so SOD-like activity is probably effected by the total antioxidant. Moreover, it could be concluded that four different extraction methods had significant differences. The highest value, by AEC, was over 2.2 times than the lowest one, by AEB. AEC and AED showed more effective effect on the SOD-like activity.

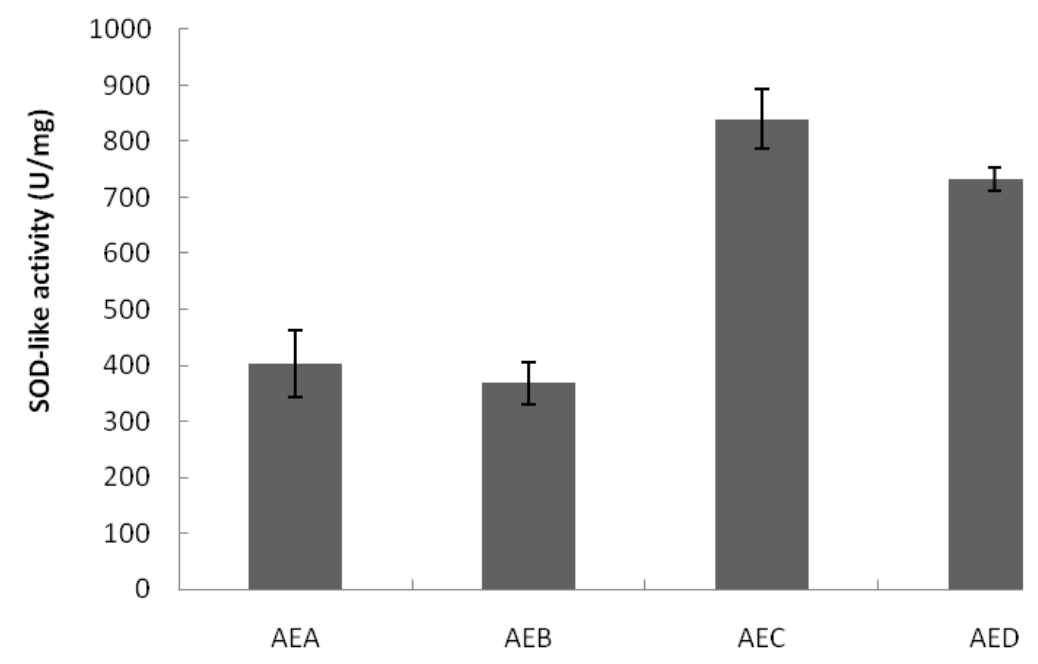

Figure 1. SOD-like activity of extracts from the root of $A$. kolomikta 


\subsubsection{DPPH Scavenging Radical Activity Assays}

DPPH is a stable free radical used for measuring the electron-donating capacity (Cheorun et al., 2003). The DPPH radical-scavenging activities were shown in Figure 2. It indicates that the positive control Trolox showed a strong DPPH radical-scavenging activity (EC50, $246 \mu \mathrm{g} / \mathrm{ml}$ ), AEC and AED even showed stronger radical-scavenging activity (EC50, $152.2 \mu \mathrm{g} / \mathrm{ml}$ and EC50, $193.3 \mu \mathrm{g} / \mathrm{ml}$ ). Moreover, fractions AEA and AEB also showed strong DPPD radical-scavenging activities (EC50, 690.1 $\mu \mathrm{g} / \mathrm{ml}$ and EC50, $870.6 \mu \mathrm{g} / \mathrm{ml}$ ), though which is a little lower compare with the positive control Trolox $(\mathrm{p}<0.05)$. A lower EC50 value indicated a higher DPPH radical-scavenging activity in this experiment.

The extract fractions are highly complex in their constituent structure, however the extracts with different extraction steps may have a different ratio of the same substance and the same substances may have a different immunoreactive rank. The immunoreactive effect also can be compared with other people's research results to see whether this extraction method of this plant with low consumption is valuable or not. This method represents less degradation of all the active ingredients compared with other methods $\left(40^{\circ} \mathrm{C}\right.$ Water Extraction Method: about 9\%) (Liu et al., 2010). By the two methods of antioxidant activities assay, the same result in SOD activity and DPPH-scavenging activity were observed and the order is: AEC $>$ AED $>A E A>A E B$. It was considered that in this experiment, high content of total antioxidant in AEC resulted in the high antioxidant activity.

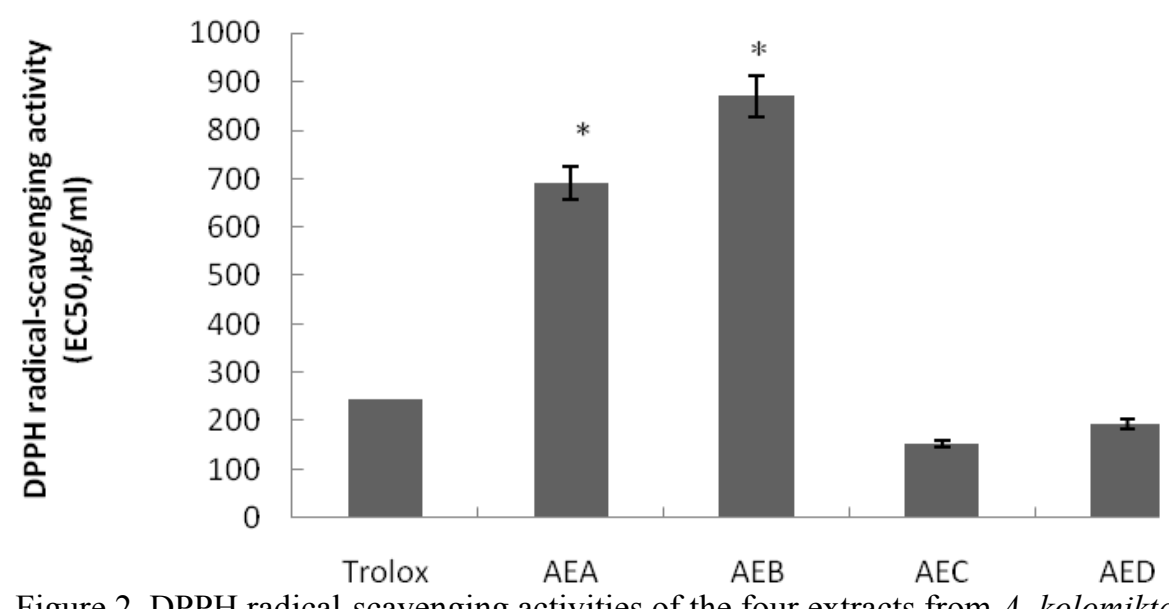

Figure 2. DPPH radical-scavenging activities of the four extracts from A. kolomikta

Data are expressed as means \pm S.D. of three independent experiments $\left({ }^{*} p<0.05\right.$ in comparison with Trolox).

\subsection{Evaluation of DLD-1 Cells}

\subsubsection{Anti-Proliferative Activities of the Different Extracts on the DLD-1 Cells}

Anti-proliferative activities of the different extracts with various concentrations of extracts $(12.5,25,50 \mu \mathrm{g} / \mathrm{ml})$ from A. kolomikta on the growth of the human colon cancer DLD-1 cell line in vitro are summarized in Figure3.Results showed that, not all the extracts affect DLD-1 cell proliferation with varying degrees of inhibition, such as AED and AEB at $12.5 \mu \mathrm{g} / \mathrm{ml}$. All of the concentrations of AEA and AEC showed significant anti-proliferative effects. The cell survival rates induced by AEA was $22.9 \%$ at the concentration of $12.5 \mu \mathrm{g} / \mathrm{ml}$ for $48 \mathrm{~h}$ treatment of DLD-1 cells and by AEC was $30.8 \%$ at the concentration of $50 \mu \mathrm{g} / \mathrm{ml}$ at $48 \mathrm{~h}$ treatment of DLD-1 cells, respectively. However, treatment at the concentration $50 \mu \mathrm{g} / \mathrm{ml}$ showed the strongest inhibiting effect point on DLD-1 cells proliferation at $48 \mathrm{~h}$, which was $30.0 \%$. The extracts of AED at all concentrations just showed indistinctive inhibited proliferation of DLD-1 cells at 24h, whereas other periods ( $12 \mathrm{~h}$ and $48 \mathrm{~h}$ ) showed slight recovery. 

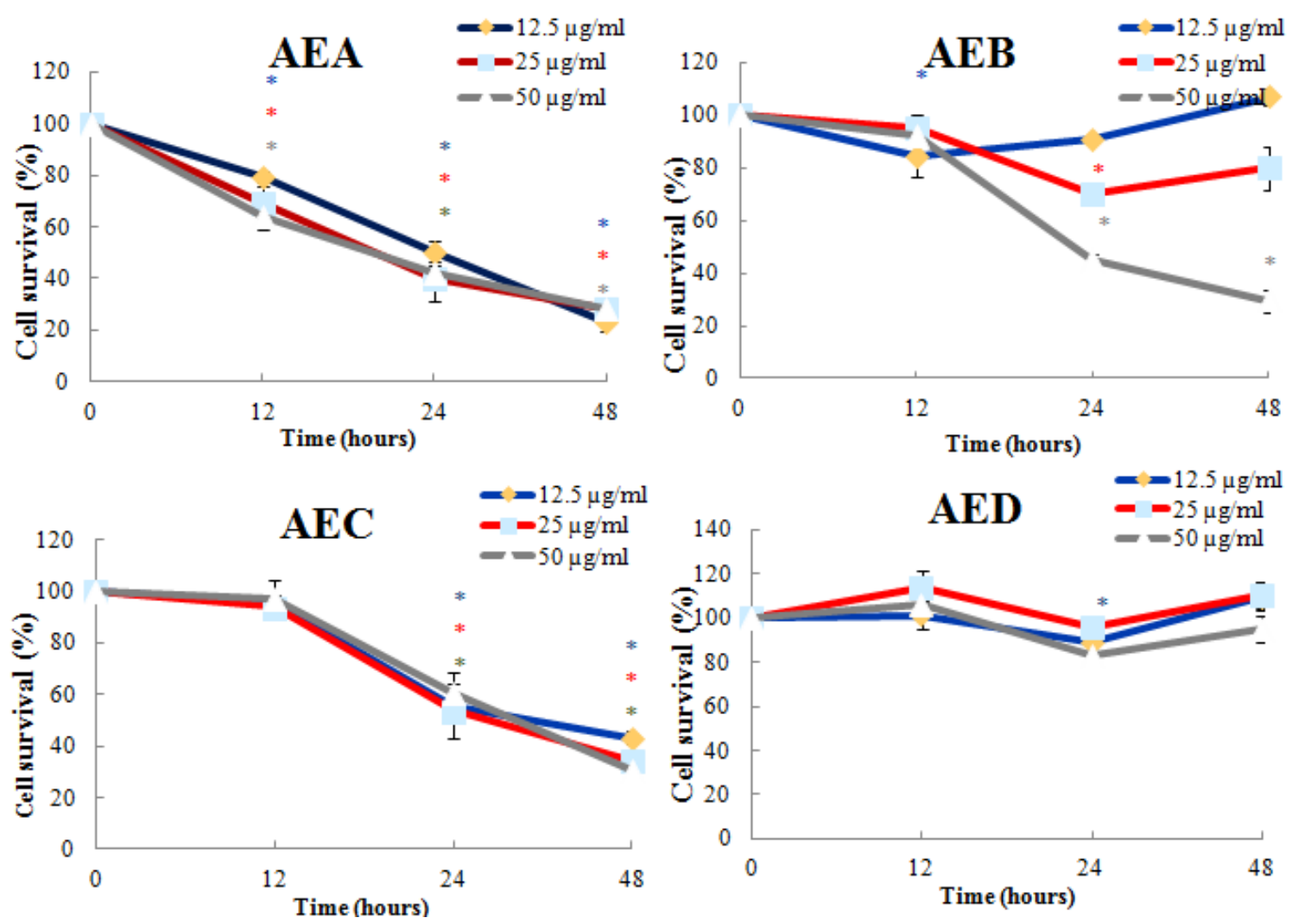

Figure 3. Anti-proliferation activities of four fractions of extracts from A. kolomikta on colon cancer DLD-1 cells. Data are expressed as means \pm S.D. of three independent experiments $\left({ }^{*} p<0.05,{ }^{* *} p<0.01\right.$ in comparison with control)

\subsubsection{Percentage Changes of Apoptotic Cells}

Flow cytometry is a single-cell quantitative flow cytometry analysis and sorting technology. Flow cytometry is a highly developed monoclonal antibodies and immunocytochemical techniques, laser and computer science and comprehensive utilization of high-tech products. This technique can be used to a cell flowing through the optical or electronic detector for continuous multiple parameters analysis. The data obtained by flow cytometry can be painted into a one-dimensional histogram, or two or three-dimensional scattergram. Based on the results of Figure 3, AEA and AEC were chosen to determine the apoptosis rate of DLD-1 cells. The apoptosis cells detected using flow cytometry were shown in Figure4. Compared with the control 1.07\%, when treated with AEA and AEC at a concentration of 25 and $100 \mu \mathrm{g} / \mathrm{ml}$ for $48 \mathrm{~h}$, the percentages of apoptosis cells significantly increased from $1.49 \%$ to $13.99 \%$ and from $0.85 \%$ to $17.30 \%$ shown from a to $\mathrm{b}$ and $\mathrm{c}$ to $\mathrm{d}$, which suggests that both AEA and AEC have abilities on enhancing cancer cells apoptosis. Meanwhile, both of them induced DLD-1 cells apoptosis in a dose-dependent manner. 

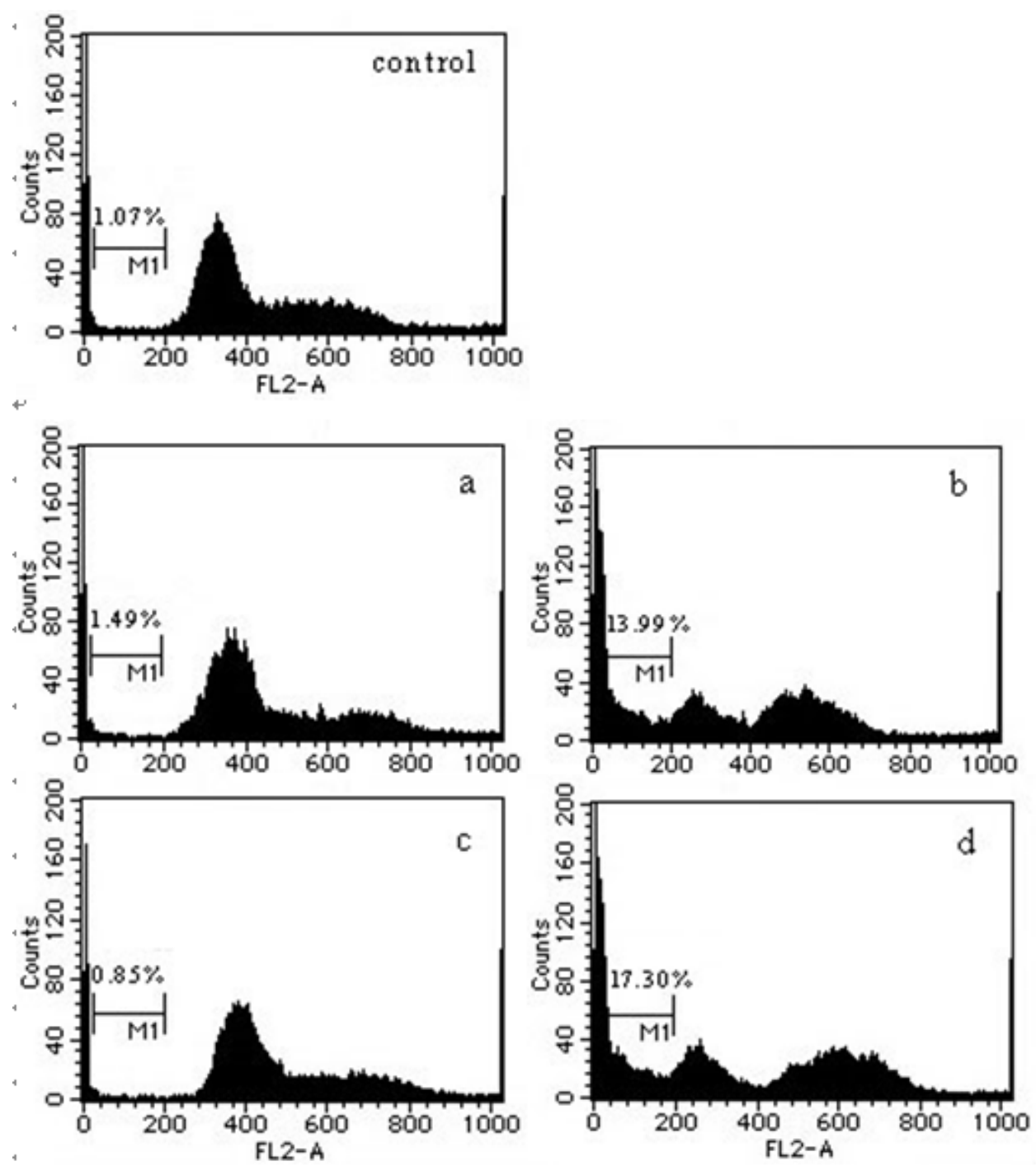

Figure 4. Percentages of apoptosis of DLD-1 cancer cells treated with A. kolomikta

DLD-1 cells were incubated for $48 \mathrm{~h}$ with AEA and AEC. a: fraction AEA $(25 \mu \mathrm{g} / \mathrm{ml})$; b: fraction AEA (100 $\mu \mathrm{g} / \mathrm{ml})$; c: fraction AEC (25 $\mu \mathrm{g} / \mathrm{ml})$; d: fraction AEC $(100 \mu \mathrm{g} / \mathrm{ml})$.

AEA, AEB, AEC and AED, four extractions were used for evaluating the anti-proliferative effect on DLD-1 cells, which were investigated by WST assay to detect the anti-proliferation effects. AEA and AEC both showed significant anti-proliferative effects, inhibited DLD-1 cells proliferation in a time-dependent manner. The anticancer bioactivity compounds of $A$. kolomikta probably existed in both AEA and AEC, and these two extracts induced anti-proliferation effect on the cancer cell through an apoptosis-inducing mechanism. Compared with previous research (Liu et al. 2010), this study utilized low consumption with lower extraction temperature, lower alcohol concentration using and simpler operating conditions, almost equals the anti-proliferation effect on the cancer cell by the apoptosis-inducing mechanism in the extracts, such as AEA and AEC fractions. Analysis of the contrast in Table 1, which contains the main antioxidant components figures and Figure 3, which demonstrates the anti-proliferation of four extracts, indicates polyphenol and flavonoids play more active roles in anti-proliferation.

\subsection{Evaluation of Macrophage RAW 264.7 Cells}

\subsubsection{The Effect of Extracts on the Proliferation of the Macrophage RAW 264.7 Cells}

The immunological activities of AEB and AED on macrophage cells are shown in Figure 5 (AEA and AEC had no obvious effects on macrophage proliferation). The effect of four extracts, at the concentration of $2.5-25 \mu \mathrm{g} / \mathrm{ml}$, 
stimulated the proliferation of the macrophage raw 264.7 cells. Figure 5, demonstrates significantly that both AEB and AED showed the stimulatory effect on cell proliferation at concentration of $2.5 \mu \mathrm{g} / \mathrm{ml}$ to $12.5 \mu \mathrm{g} / \mathrm{ml}$, and achieved the highest level at the concentration of $12.5 \mu \mathrm{g} / \mathrm{ml}$, which were $264 \%$ and $250 \%$, respectively. Furthermore, after this the stimulation effect lowered with upper dosage. Incubation with AEB at $1.6-12.5 \mu \mathrm{g} / \mathrm{m}$ induced cell survival rate in the range of $167 \%$ to $264 \%$ showed that AEB more effectively stimulated macrophage proliferation than AED.

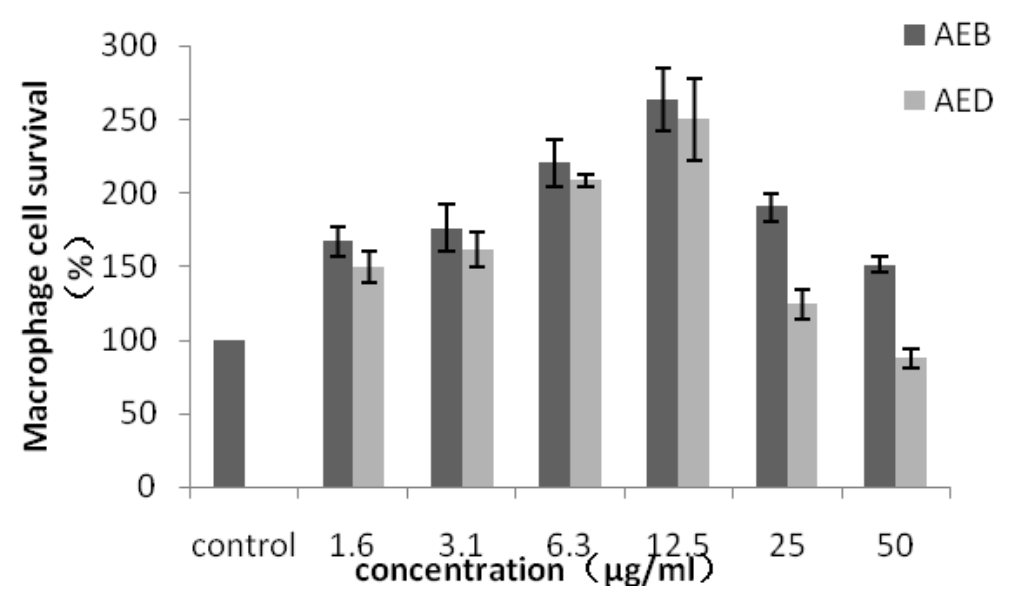

Figure 5. Immunological activities of AEB and AED on Macrophage cells $(\mathrm{P}<0.05)$

Cells were incubated with various concentrations of AEB and AED (1.6, 3.1, 6.3, 12.5, 25 and $50 \mu \mathrm{g} / \mathrm{ml})$ for $24 \mathrm{~h}$. Data are expressed as means \pm S.D. $(\mathrm{n}=3),\left({ }^{*} p<0.05,{ }^{* *} p<0.01\right.$ in comparison with control).

\subsubsection{Effect of AEB and AED on Nitric Oxide Production}

According to previous papers, $\mathrm{NO}$ is a highly reactive free radical which can form a number of oxidation products such as $\mathrm{NO}_{2}, \mathrm{NO}_{2}-, \mathrm{N}_{2} \mathrm{O}_{3}$ and S-nitrosothiols, which participates in the physiology and pathophysiology of many systems, thus NO can be used as a quantitative index of macrophage activation (Diouf, Stevanovic, \& Boutin, 2009).

The stimulation effect of AEB, AED on RAW 264.7 cells at $24 \mathrm{~h}$ as an indication of NO production is shown in Figure 6. The data indicated that, treated with both AEB and AED at a concentration of 3.1-12.5 $\mu \mathrm{g} / \mathrm{ml}$, the NO production was significantly higher than the control $(\mathrm{p}<0.05)$. Furthermore, the quantitative values of three concentrations were approximate. Moreover, treatment with the NO concentration increased in a dose-depended manner with both fractions. It suggests that both AEB and AED acted on macrophage RAW 264.7 cells up-regulating NO production observably and they up-regulated in a dose-dependent manner.

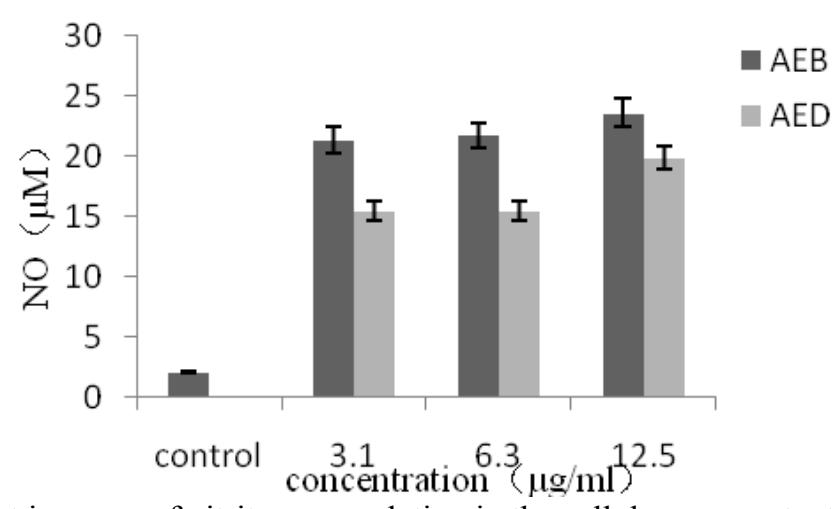

Figure 6. Dose-dependent increase of nitrite accumulation in the cellular supernatant of AEB, AED-stimulated RAW 264.7 cells after $24 \mathrm{~h}$ as an indication of NO production

Data are expressed as means \pm S.D. $(\mathrm{n}=3)\left({ }^{*} p<0.05,{ }^{* *} p<0.01\right.$ in comparison with control). 


\subsubsection{Protective Effect of AEB and AED on Macrophage Viability}

Doxorubicin (DOX) is an anthracycline antibiotic used in cancer chemotherapy and works by intercalating DNA. Due to the importance in chemotherapy many types of cancer, the researchers spend great concentration on preventing or attenuate the aspect adriamycin administration. The macrophages survival rate showed a decrease treated with DOX, which was about $16.24 \%$. When incubated DOX-induced macrophages with of AEB from 3.1 $\mu \mathrm{g} / \mathrm{ml}$ to $12.5 \mu \mathrm{g} / \mathrm{ml}$, the cell survival rate was increased from $65.13 \%$ to $81.67 \%$, in a dose-dependent manner. Further, incubation with AED, cell survival increased from about $51.35 \%$ to $76.18 \%$ (Figure 7 ). However, incubating AEB and AED, the viability of macrophages was significantly higher than that of the incubation with DOX. In other words, incubated DOX-induced macrophages with various concentrations of AEB and AED extracts of roots of $A$. kolomikta, increased the cell survival rate in a dose-dependent manner.

In macrophage activation assay, results showed that AEB and AED in the range of 1.6-12.5 $\mu \mathrm{g} / \mathrm{ml}$, stimulated RAW 264.7 cells proliferation in a dose-dependent manner (Figure 5) and AEB proved to be more effective in this immunomodulatory activity. Compared with results from other research (Schepetkin \& Quinn, 2006), on the effect of stimulation of RAW 264.7 cell proliferation; results from this study result are highly competitive. Furthermore, results of NO production also showed that, incubation with AEB and AED resulted in a marked up-regulation of $\mathrm{NO}$ production.

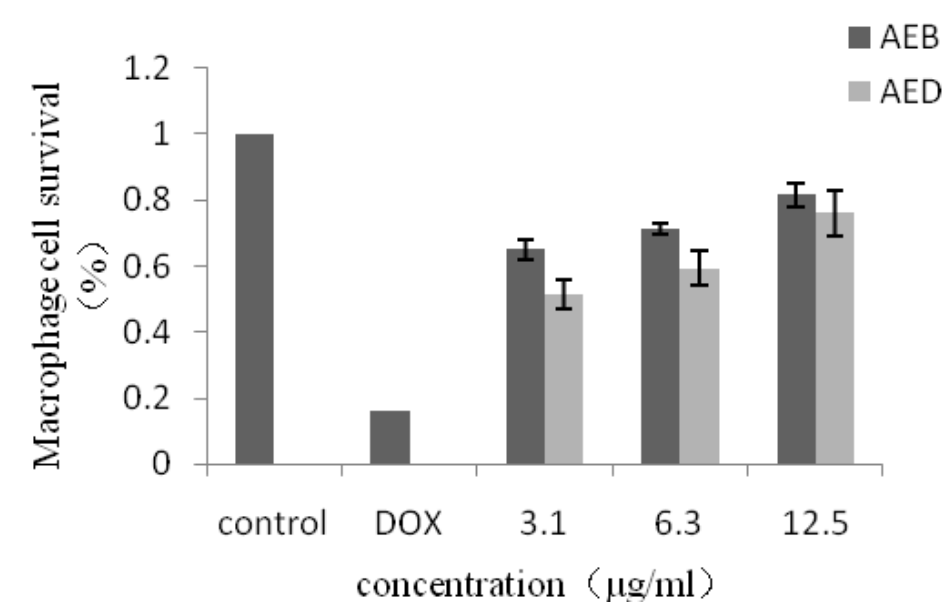

Figure 7. Effect of AEB and AED from the root of A. kolomika on DOX-induced macrophage RAW 264.7 cells survival. RAW 264.7 cells were incubated with DOX $(5 \mu \mathrm{M})$ in the presence or absence of different concentrations of AEB and AED (3.1, 6.3 and $12.5 \mu \mathrm{g} / \mathrm{ml})$ for $24 \mathrm{~h}$

Data are expressed as means \pm S.D. of three independent experiments $\left({ }^{* *} p<0.01\right.$ in comparison with DOX).

\section{Conclusions}

The extracts were obtained from the root of A. kolomikta by Ethanol-hot water combination extraction and showed a strong SOD-like activity, DPPH radical scavenging activity, a stimulatory effect on cell proliferation, the NO production and the protection of the macrophages from DOX damage. These results indicate that the antioxidant ingredients extracted from the root of A. kolomikta could be a potential and effective biological material that can be utilized as a natural immunomodulator source for the medicinal and food industry. The isolation, purification, characterization and functional effects of the roots of $A$. kolomikta should be explored in the future.

\section{References}

Cai, Y. Z., Luo, Q., Sun, M., Corke, H. (2004). Antioxidant activity and phenolic compounds of 112 traditional Chinese medicinal plants associated with anticancer. Life Science, 74(14), 2157-2184. http://dx.doi.org/10.1016/j.lfs.2003.09.047

Diouf, P. N., Stevanovic, T., \& Boutinb, Y. (2009). The effect of extraction process on polyphenol content, triterpene composition and bioactivity of yellow birch (BetulaalleghaniensisBritton) extracts. Industrial Crops and Products, 30(2), 297-303. http://dx.doi.org/10.1016/j.indcrop.2009.05.008

Dubois, M., Gilles, K. A., Hamilton, J. K., Rebers, P. A., \& Smith, F. (1956). Colorimetric method for 
determination of sugars and related substances. Analytical Chemistry, 28, 350-356. http://dx.doi.org/10.1021/ac60111a017

Gorinstein, S., Haruenkit, R., Poovarodom, S., Park, Y. S., Vearasilp, S., Suhaj, M., ... Jang, H. G. (2009). The comparative characteristics of snake and kiwi fruits. Food and Chemical Toxicology, 47(8), 1884-1891. http://dx.doi.org/10.1016/j.fct.2009.04.04

Jo, C., Son, J. H., Lee, H. J., \& Byun, M. W. (2003). Irradiation application for color removal and purification of green tea leaves extract. Radiation Physics and Chemistry, 66(2), 179-184. http://dx.doi.org/10.1016/S0969-806X(02)00273-6

Leung, M. Y. K., Liu, C., Koon, J. C. M., \& Fung, K. P. (2006). Polysaccharide biological response modifiers. Immunology Letters, 105(2), 101-114. http://dx.doi.org/10.1016/j.imlet.2006.01.009

Liu, F., Ooi, V. E. C., Liu, W. K., \& Chang, S. T. (2000). Immunomodulation and antitumor activity of polysaccharide-protein complex from the culture filtrates of a local edible mushroom, Tricholoma lobayense. General Pharmacology: The Vascular System, 27(4), 621-624. http://dx.doi.org/10.1016/0306-3623(95)02058-6

Liu, J. Q., Zhang, Z. Y., Xing, G. Q., Hu, H. H., Sugiura, N., \& Keo, I. (2010). Potential antioxidant and antiproliferative activities of a hot-water extract from the root of TonhKhidum. Oncology Letters, 1(2), 383-387. http://dx.doi.org/10.3892/ol_00000068

Mates, J. M., Perez-Gomez, C., \& Nunez, de C. I. (1999). Antioxidant enzymes and human diseases.Clinical Biochemistry, 32(8), 595-603. http://dx.doi.org/10.1016/S0009-9120(99)00075-2

Mau, J. L., Lin, H. C., \& Song, S. F. (2002). Antioxidant properties of several specialty mushrooms. Food Research International, 35(6), 519-526. http://dx.doi.org/10.1016/S0963-9969(01)00150-8

Nakajima, Y., Sato, Y., \& Konishi, T. (2007). Antioxidant small phenolic ingredients in Inonotusobliquus (persoon) Pilat (Chaga). Chemical and Pharmaceutical Bulletin, 55(8), 1222-1226. http://dx.doi.org/10.1248/cpb.55.1222

Schepetkin, I. A., \& Quinn, M. T. (2006). Botanical polysaccharides: macrophage immunomodulation and $\begin{array}{llll}\text { therapeutic } & \text { potential. International }\end{array}$ http://dx.doi.org/10.1016/j.intimp.2005.10.005

Sousa, A., Ferreira, I. C. F. R., Barros, L., Bento, A., \& Pereira, J. A. (2008). Effect of solvent and extraction temperatures on the antioxidant potential of traditional stoned table olives "alcaparras". LWT - Food Science and Technology, 4l(4), 739-745. http://dx.doi.org/10.1016/j.lwt.2007.04.003

Su, X. G., Duan, J., Jiang, Y. M. Shi, J., \& Kakuda, Y. (2006). Effects of soaking conditions on the antioxidant potentials of oolong tea. Journal of Food Composition and Analysis, 19(4), 348-353. http://dx.doi.org/10.1016/j.jfca.2005.02.005

Wasser, S. P. (2002). Medicinal mushrooms as a source of antitumor and immunomodulating polysaccharides. Applied Microbiology Biotechnology, 60(3), 258-274. http://dx.doi.org/10.1007/s00253-002-1076-7

Xu, H. S., Yao, L., Sun, H. X., \& Wu, Y. W. (2009). Chemical composition and antitumor activity of different polysaccharides from the roots of Actinidia eriantha. Carbohydrate Polymers, 78(2), 316-322. http://dx.doi.org/10.1016/j.carbpol.2009.04.007

Yang, B., Wang, J., Zhao, M., Liu, Y., Wang, W., \& Jiang, Y. (2006). Identification of polysaccharides from pericarp tissues of litchi (Litchi chinensisSonn.) fruit in relation to their antioxidant activities. Carbohydrate Research, 341(5), 634-638. http://dx.doi.org/10.1016/j.carres.2006.01.004

Yang, X., Guo, D., Zhang, J., \& Wu, M. (2007). Characterization and anti-tumor activity of pollen $\begin{array}{llll}\text { polysaccharide. } & \text { International } & \text { Immunopharmacology, } & 7(3),\end{array}$ http://dx.doi.org/10.1016/j.intimp.2006.11.001

Zhang, M., Chen, H. X., Huang, J., Li, Z., Zhu, C. P., \& Zhang, S. H. (2005). Effect of lycium barbarum polysaccharide on human hepatoma QGY7703 cells: Inhibition of proliferation and induction of apoptosis. Life Science, 76(18), 2115-2124. http://dx.doi.org/10.1016/j.lfs.2004.11.009

Zhao, G. H., Kan, J. Q., Li, Z. X., \& Chen, Z. D. (2005). Characterization and immunostimulatory activity of an $(1 \rightarrow 6)$-a-d-glucan from the root of Ipomoea batatas. International Immunopharmacology, 5(9), 1436-1445. http://dx.doi.org/10.1016/j.intimp.2005.03.012 